\title{
Distribution of Soil-Bound Lead Arising from Rainfall-Runoff Events at Impact Berm of a Military Shooting Range
}

\author{
Effiong Ukorebi Etim \\ Department of Chemistry, University of Ibadan, Ibadan, Nigeria \\ Email: etim242@yahoo.com
}

Received 24 February 2016; accepted 4 April 2016; published 7 April 2016

Copyright (C) 2016 by author and Scientific Research Publishing Inc.

This work is licensed under the Creative Commons Attribution International License (CC BY).

http://creativecommons.org/licenses/by/4.0/

(c) (i) Open Access

\begin{abstract}
Surface runoff from rainfall event is an important indicator of metal mobility in soil, which may enhance non-point source contamination of soil. This study is designed to assess the mobility of soil-bound lead through simulated rainfall runoff experiment and its spatial distribution within the vicinity of a berm at a major military shooting range. Contamination was more significant at the impact area of berm, indicating threefold increase in $\mathrm{Pb}(17,500 \pm 3811 \mu \mathrm{g} / \mathrm{g})$ within a space of ten years. However, the non-impact area $(459 \pm 147 \mu \mathrm{g} / \mathrm{g})$ was less contaminated. Other metals ( $\mathrm{Cu}, \mathrm{Cd}, \mathrm{Cr}, \mathrm{Ni}$ and $\mathrm{Zn}$ ) analyzed were about background levels except for $\mathrm{Cu}$ at impact area. The enrichment ratio of $\mathrm{Pb}$ in runoff sediments was mostly high for the $0.43 \mathrm{~mm}$ sediment fractions independent of rainfall condition. Principal component analysis (PCA) biplot showed strong correlation between spatial distributions of metals around the vicinity of the berm (farmlands behind the berm) with concentrations on the impact berm soil. Surface runoff simulated on impact area soil had high concentrations of $\mathrm{Pb}(40.4-65.6 \mu \mathrm{g} / \mathrm{mL})$ which could further lead to enrichment of soil-Pb levels within the vicinity of the berm. Decontamination measure is therefore required to minimize extensive contamination of surrounding soils of the impact berm due to rainfall runoff events.
\end{abstract}

\section{Keywords}

Lead, Soil Contamination, Enrichment Ratio, Sediment, Shooting Range

\section{Introduction}

Soil contamination with toxic trace metals, is a major environmental problem largely attributed to industrial

How to cite this paper: Etim, E.U. (2016) Distribution of Soil-Bound Lead Arising from Rainfall-Runoff Events at Impact Berm of a Military Shooting Range. Journal of Environmental Protection, 7, 623-634.

http://dx.doi.org/10.4236/jep.2016.75056 
activities and improper waste disposals. However, activities at shooting ranges are gradually accounting for a significant source of this toxic trace metal contamination of soils [1]-[3]. The sources of concern have been generally linked to the use of copper cap-lead bullets of different caliber for shooting activities. Lead which is about $90 \%$ - 95\% content of bullet [4] is therefore the trace metal contaminant of primary concern and abundant in most shooting range soils especially at the impact berm (or bullet trap). In view of this, shooting ranges are considered an important source of soil-Pb contamination accounting for about the second largest source of $\mathrm{Pb}$ contamination ranging from $1000 \mu \mathrm{g} / \mathrm{g}$ to $90,000 \mu \mathrm{g} / \mathrm{g}$ of annual soil deposition in different countries [5]-[12]. High lead levels are usually concentrated at the impact berm soils of the shooting range where the bullet pellets are mostly deposited. Fragmentation occurs when previously deposited pellets are continuous being impacted by new ones producing fine corroded particulates of metallic lead in the soils [13]-[15]. Depending on soil conditions these corroded particles of metallic lead could be mineralized and transported by rainfall surface run-offs across large areas of uncontaminated soils resulting in contamination of arable farmland and aquatic ecosystems. Consequently, using rainfall simulators various rainfall run-off studies have been conducted to assess transport mechanism of metals and non-metal contaminants in soil environment [16] [17].

One important range environment that may elicit research interest in this regard is the Ibadan military shooting range. The range has been active for well over 60 years, but over the last ten years there has been a gradual cessation of shooting activity, bullet fragments and spent short abound around the berm soils. The sizes and conditions of these fragmented pellets which has not been established will to an-extend determine its level of migration during rainfall surface run-offs. The range is sited within the tropical humid climate with an average rainfall intensity of 100 to $300 \mathrm{~mm} / \mathrm{hr}$. Depending on soil chemistry; these climatic conditions could enhance mobility of fragmented lead shot from impact berm to surrounding soils mainly used for agricultural purpose, since there are no well-defined drainages within the range. Previous assessment studies carried out in 2004 on the range showed lead levels as high as $5680 \pm 2700 \mu \mathrm{g} / \mathrm{g}$ on the impact berm [18]. This research study will be the first to be conducted to simulate varying rainfall conditions has it relates to mobility and spatial distribution of soil-bound lead adapted from an impact berm of a major military shooting range located in a tropical humid climate of West Africa.

This study is therefore designed to assess the mobility of soil-bound lead through a simulated rainfall runoff experiment on contaminated soils from the berm. The berm was classified into impact (front slope) and nonimpact (back slope) areas. Secondly, to assess spatial distribution of lead at varying distances away from impact and non-impact area of berm through the determination of $\mathrm{Pb}$ concentrations in soils as well as properties such as $\mathrm{pH}$, particles size distribution and organic carbon. Finally, to assess the current $\mathrm{Pb}$ levels at the berm in respect to previous study. An experimental system was setup to simulate the runoff pollution process on contaminated soils from the berm. Runoff simulations were performed on different rainfall intensities. Enrichment ratio and time series data of lead levels in different graded particle sizes of discharged sediment at different intensities were obtained and analyzed.

\section{Material and Methods}

\subsection{Site Description and Sample Collection}

The sampling area consists of a $100 \mathrm{~m}$ long, $18 \mathrm{~m}$ wide and $20 \mathrm{~m}$ high berm. In front of the berm is a platform for target placement along with the 100 to $500 \mathrm{~m}$ firing lines. Behind the berm are scattered plots of farm lands (Figure 1). Storm water run-offs from the berm directly drains into surrounding farm lands, has there are no visible drainage channels within the vicinity. The site directly lies within the humid tropical climates with approximately six to eight months of rainfall at variable intensity. When the shooting range is active, targets are placed at the bottom of the berm and rifle fire is directed towards the target at a horizontal/upward angle. For the rainfall run-off experiment, three sampling points each on the front slope (impact area) and back slope (non-impact area) of berm were identified for core polluted soil sample collection. At each core polluted soil sampling location, top soil $(0-15 \mathrm{~cm})$ samples were taken at multiple spots of 3 by $3 \mathrm{~m}$. The three core polluted soil samples from each of the front and back slope were then mixed together to obtain a composite sample for the experiment. Large quantity (approximately $50 \mathrm{~kg}$ ) of these core polluted soil samples was obtained. Furthermore, to assess the spatial distribution of $\mathrm{Pb}$ on the surrounding top soils, four sampling points each were identified at 10, 20, 30, 50 and $75 \mathrm{~m}$ away from the front and farmlands at the back slope of the berm. A total of two core polluted soil samples and forty surrounding soil samples were obtained. Two control soil samples were 


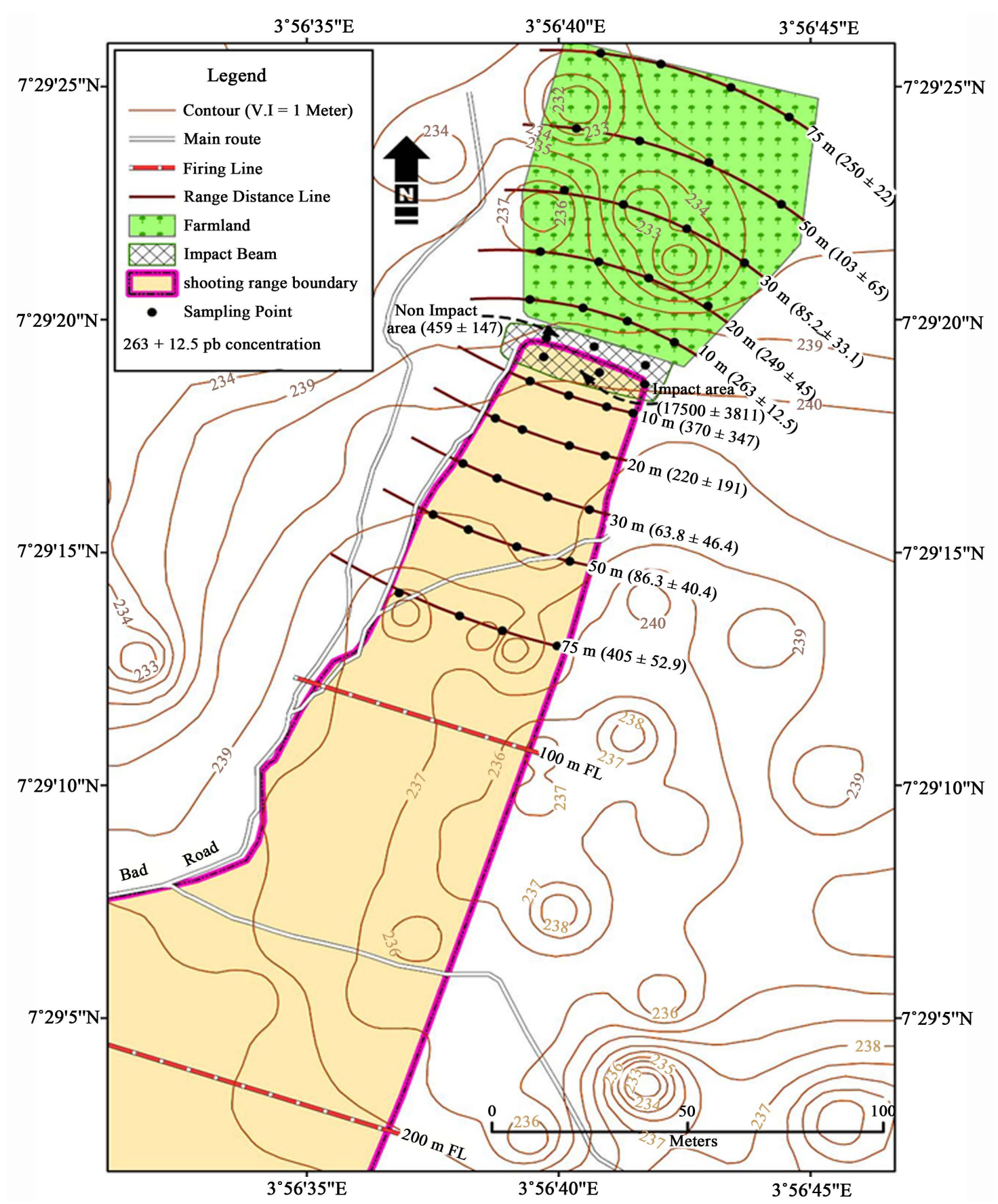

Figure 1. Map showing sample locations and corresponding average concentrations of $\mathrm{Pb}$.

obtained about $2 \mathrm{~km}$ away from the range. Sampling was carried out on dry days with no significant rainfall events. Sampling was done using a stainless soil scoop and mixed and subsequently stored in labeled plastic bags and transported to the laboratory for further processing and analysis.

\subsection{Soil Preparation and Analysis}

The soil samples were air dried in the laboratory and large pieces of debris were removed. Thereafter, core polluted soil samples were well aggregated and sieved through $4 \mathrm{~mm}$ sieve to simulate actual field condition while other soil samples were sieved using $2 \mathrm{~mm}$ sieve. The electrometric method (Jenway $3510 \mathrm{pH}$ meter) was used 
for soil $\mathrm{pH}$ determination. Mechanical properties and organic carbon were determined using the hydrometer method [19] and Walkley and Black method [20] respectively. The ecologically significant fraction of the metals in the various samples was extracted by digesting $5.0 \mathrm{~g}$ of the soil with $50 \mathrm{ml} 2 \mathrm{M} \mathrm{HNO}_{3}$ at $120^{\circ} \mathrm{C}$ for 2 hours [21].

\subsection{Rainfall-Runoff Experiment}

The setups compose mainly of a soil box and a rainfall simulator as described by Hignett [22] and Yi Zheng [17] in Figure 2. The soil box is made of a transparent polymethyl methacrylate material $(100 \mathrm{~cm}$ in length, $15 \mathrm{~cm}$ in width and $30 \mathrm{~cm}$ in depth) and fixed on a wooden frame for support. At the lower end of the soil box, a V-shaped weir was installed which directs water through a $10 \mathrm{~cm}$ long trough. For each experiment, the soil box was first packed with clean dry sands to form a bottom layer of about $25-28 \mathrm{~cm}$ thickness. Subsequently, a well mixed polluted soil sample was packed on top of it to form a $2.2-2.5 \mathrm{~cm}$ thick soil layer. The soil box was then covered with a plastic hood until the rainfall experiment started. The packed soil was first sampled prior to the rainfall simulation for heavy metal determination.

A rain module, peristaltic pump and a flow meter was used in the construction of the rainfall simulator. When the simulator was in operation, the pump delivered water ( $\mathrm{pH}$ 5.32) with closely similar characteristic to rain water from a tank to the rain module. The flow meter was used to monitor and control the delivery rate of water (i.e. rainfall intensity) through the needles on the rain module. The rain gauge was then placed in the soil box to record rainfall intensity and the output was manually used to adjust the delivery rate of the pump to the desired rainfall intensities. Once the steadiness and spatial uniformity of the rainfall intensity was achieved, the plastic hood was removed and the experiment started. The experiment was run for three different rainfall intensities to simulate conditions for light rainfall-80 mm/hr, moderate rainfall- $150 \mathrm{~mm} / \mathrm{hr}$ and heavy rainfall- $200 \mathrm{~mm} / \mathrm{hr}$ (obtainable in tropical climatic regions). For each of the rainfall intensity, five different runoff samples were intermittently collected at roughly equal time intervals.

The runoff samples for each experiment were collected using a $5 \mathrm{~L}$ clear plastic container. The collection started immediately after the runoff was observed. The time for collecting one sample, ranged between 2 to 5 minutes depending on the rainfall intensity. The sediments from each runoff samples were partitioned into four particulate sizes by filtering through a $0.425,0.250,0.180$ and $0.150 \mathrm{~mm}$ sieves. The filtrate was stored in clean plastic containers for subsequent determination of heavy metals while the sediments were air dry in the laboratory and stored for heavy metal analysis. A $100 \mathrm{ml}$ portions of the filtrates was concentrated to $25 \mathrm{ml}$ using $2 \mathrm{ml}$ concentrated $\mathrm{HNO}_{3}$ while $1.0 \mathrm{~g}$ of each sized sediment samples was extracted using $50.0 \mathrm{ml} 2 \mathrm{M} \mathrm{HNO}_{3}$ [21]. The filtrate, sediment and soil extracts were analyzed for $\mathrm{Pb}, \mathrm{Cd}, \mathrm{Cr}, \mathrm{Co}, \mathrm{Ni}$ and $\mathrm{Zn}$ using the flame atomic spectrophotometer (Buck Scientific, model 200 A).

Strict quality control measures were followed in all the analysis. The reagents used were of analytical grade. To check the reproducibility of the experiment; $80 \mathrm{~mm} / \mathrm{hr}$ and $150 \mathrm{~mm} / \mathrm{hr}$ rainfall intensities was duplicated for one polluted soil sample. The repeated experiment generated similar results but only one was reported (Table 1). The rainwater used for the experiment was constantly checked for background metal concentrations, results showed negligible levels. Recovery study of the extraction procedure was carried out by spiking four previously analyzed soil and five runoff sediment samples with prepared AnalaR grade standards of $\mathrm{Pb}, \mathrm{Cd}, \mathrm{Cr}$ and $\mathrm{Ni}$. The average percentage recoveries were $\mathrm{Pb}(86.3 \pm 7.42)$, $\mathrm{Cd}(92.1 \pm 9.72)$, $\mathrm{Cr}(82.6 \pm 7.22)$ and $\mathrm{Ni}(89.9 \pm 3.96)$.

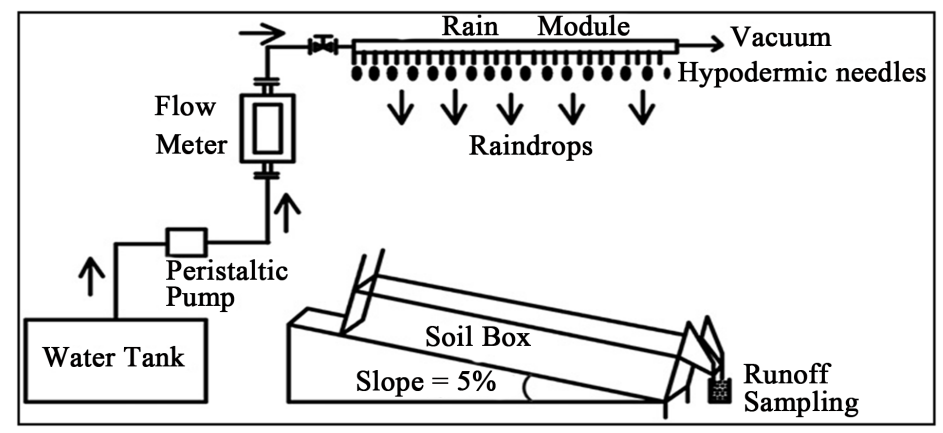

Figure 2. Diagram of experimental model (Yi Zheng et al., 2012). 
Table 1. Result of duplicated experiment carried out on one polluted soil sample.

\begin{tabular}{ccccc}
\hline Descriptions/Rainfall condition (mm/hr) & 80 & 80 & 150 & 150 \\
\hline Total number of runoff collected & 5 & 5 & 5 & 5 \\
Total volume of runoff collected (L) & 9.7 & 9.5 & 12.3 & $3-3.4$ \\
Time intervals (min) & $2-2.7$ & $2-2.2$ & $3-3.6$ & 51.1 \\
Total sediment mass (g) & 32.6 & 31.4 & 5 & 5 \\
Number of sediment of 0.43 mm size fraction separated & 5 & 5 & 5 & 5 \\
Number of sediment of 0.25 mm size fraction separated & 5 & 4 & 5 & 5 \\
Number of sediment of 0.18 mm size fraction separated & 4 & 5 & 5 & $16,273 \pm 4830$ \\
Number of sediment of 0.15 mm size fraction separated & 5 & $10,378 \pm 8572$ & $16,461 \pm 4476$ & 5 \\
Average Pb concentration $(\mu \mathrm{g} / \mathrm{g})$ in 0.43 mm fractions only & $10,203 \pm 7189$ & 5 & 5
\end{tabular}

\subsection{Statistical Data Analysis}

The Paleontological Statistic software (PAST version 1.38) and Microsoft Excel (2007 version) were used for statistical evaluation of data. Principle component analysis (PCA) and analysis of variance were performed on the data set to assess metal variability, categorization, and the relationship between sample data set at varying locations. Furthermore, the enrichment ratio (ER) and accumulation factors were derived. Enrichment ratio is the ratio between the average concentration of the metal in the discharge sediment and its concentration in the original soil surface layer.

$$
\operatorname{ER}\left(T_{i}\right)=\operatorname{CS}(T i) / C_{o}
$$

where $C_{o}$ is concentration of each metals in the original soil sample, $\mathrm{CS}(\mathrm{Ti})$ is the average concentration of metals in the sediment for the duration of the rainfall Ti.

The accumulation factor is defined as the ratio of the heavy metal concentration at different sample locations to the geometric mean of the control concentration of the corresponding metal.

\section{Results and Discussion}

\subsection{Lead Levels in Soil}

The general physicochemical properties of soil (Table 2) on the berm and its surrounding are similar to previously reported soil conditions [18]. A generally reducing soil pH (5.96 - 6.43) and high organic matter content (5.08\% - 5.91\%) characterized the area, owing to its tropical climatic condition. The textural property indicates loamy soil with high percent sand and silt contents. These soil properties $(\mathrm{pH}$, organic carbon and mechanical property) were not significant different across the various sampling points within the study area due to its geology. Table 3 shows average metal levels in soils at varying distances $(0$ to $75 \mathrm{~m})$ from the elevated berm. Higher levels of $\mathrm{Pb}$ were found in soils compared to other metals with a distribution order of $\mathrm{Pb}>\mathrm{Cu}>\mathrm{Zn}>\mathrm{Cr}>\mathrm{Ni}>$ $\mathrm{Cd}$. Lead from spent shot and $\mathrm{Cu}$ from bullet casings being the primary pollutant of concern in shooting range soils [2] [23]. Most of the $\mathrm{Pb}(17,500 \pm 3811 \mu \mathrm{g} / \mathrm{g})$ is present in the impact area of the berm with accumulation factor of 583, which is the sink for spent ammunition from firing activities at the range. The non-impact area is less contaminated with $\mathrm{Pb}(459 \pm 147 \mu \mathrm{g} / \mathrm{g})$ having accumulation factor of 15.3 and not directly receiving spent shots. Lead at impact area of the berm is comparable to most oversea ranges which often time contend levels in excess of 15,000 $\mu \mathrm{g} / \mathrm{g}$. [24]-[28]. Generally, Pb decreases as distance increases away from the berm (0 to $50 \mathrm{~m}$ ) except for sharp rise in levels at the $75 \mathrm{~m}$ marks. The variations observed in $\mathrm{Pb}$ levels around cultivated farmlands behind the berm could be attributed to wash-off from the elevated berm due to micro-topography of the area. Whereas, nearness of the impact area $75 \mathrm{~m}$ mark to the $100 \mathrm{~m}$ firing line may explain the sharp rise in $\mathrm{Pb}$ levels due to dust fall from shooting activities (Figure 1). High Cu levels in and around the impact area of berm when compared to the non-impact area is due largely to presence of corroded bullet casings on the range soils. Zinc, $\mathrm{Cr}, \mathrm{Ni}$ and $\mathrm{Cd}$ were about the same levels at the berm and its surrounding soils; similarly, their levels were 
Table 2. General physicochemical properties of soil.

\begin{tabular}{ccccc}
\hline Parameter & Impact area & Non impact area & Impact area 10 to $75 \mathrm{~m}$ & Non impact area 10 to $75 \mathrm{~m}$ \\
\hline pH & $6.25 \pm 0.25$ & $6.43 \pm 0.21$ & $6.03 \pm 0.16$ & $5.96 \pm 0.29$ \\
\% Organic carbon & $2.94 \pm 0.70$ & $3.42 \pm 0.41$ & $3.23 \pm 0.51$ & $3.02 \pm 0.30$ \\
\% Organic matter & $5.08 \pm 0.23$ & $5.91 \pm 0.03$ & $5.58 \pm 0.36$ & $5.23 \pm 0.42$ \\
\% Sand & $66.8 \pm 4.10$ & $74.7 \pm 0.91$ & $71.8 \pm 6.84$ & $76.3 \pm 6.00$ \\
\% Clay & $14.1 \pm 0.77$ & $10.9 \pm 1.41$ & $13.0 \pm 3.46$ & $11.2 \pm 4.03$ \\
\% Silt & $19.0 \pm 0.30$ & $14.4 \pm 0.51$ & $15.2 \pm 3.38$ & $12.5 \pm 3.25$ \\
\hline
\end{tabular}

Table 3. Average metal levels $(\mu \mathrm{g} / \mathrm{g})$ in soil at varying distance from impact berm.

\begin{tabular}{|c|c|c|c|c|c|c|c|}
\hline Distances (m) & Direction & $\mathrm{Pb}$ & $\mathrm{Cd}$ & $\mathrm{Cr}$ & $\mathrm{Cu}$ & $\mathrm{Ni}$ & $\mathrm{Zn}$ \\
\hline 0 & ${ }^{*}$ Front & $17,500 \pm 3811$ & $2.93 \pm 0.69$ & $30.8 \pm 1.04$ & $816 \pm 293$ & $5.50 \pm 0.87$ & $72.4 \pm 20.2$ \\
\hline 10 & & $370 \pm 347$ & $3.16 \pm 1.38$ & $7.83 \pm 6.66$ & $152 \pm 164$ & $5.50 \pm 2.35$ & $37.3 \pm 20.6$ \\
\hline 20 & & $220 \pm 191$ & $2.01 \pm 1.35$ & $2.00 \pm 3.08$ & $416 \pm 149$ & $5.75 \pm 4.13$ & $104 \pm 83.9$ \\
\hline 30 & & $63.8 \pm 46.4$ & $1.51 \pm 0.63$ & $18.9 \pm 9.28$ & $32.0 \pm 8.94$ & $6.88 \pm 2.66$ & $54.6 \pm 15.6$ \\
\hline 50 & & $86.3 \pm 40.4$ & $1.10 \pm 0.29$ & $9.25 \pm 8.55$ & ND & $5.88 \pm 1.89$ & $60.6 \pm 48.7$ \\
\hline 75 & & $405 \pm 329$ & $3.36 \pm 1.67$ & $23.8 \pm 1.19$ & $15.3 \pm 15.9$ & $7.13 \pm 1.70$ & $56.4 \pm 30.6$ \\
\hline 0 & ${ }^{* *}$ Back & $459 \pm 147$ & $2.38 \pm 0.74$ & $25.8 \pm 5.3$ & $31.8 \pm 6.8$ & $4.00 \pm 0.71$ & $31.2 \pm 36.6$ \\
\hline 10 & & $263 \pm 125$ & $1.93 \pm 1.74$ & $5.63 \pm 3.84$ & $7.50 \pm 9.90$ & $6.63 \pm 3.71$ & $47.8 \pm 25.7$ \\
\hline 20 & & $249 \pm 45$ & $3.21 \pm 2.05$ & $7.25 \pm 6.65$ & ND & $8.75 \pm 6.51$ & $31.4 \pm 19.1$ \\
\hline 30 & & $85.3 \pm 33.1$ & $3.26 \pm 2.00$ & $18 \pm 11$ & ND & $3.13 \pm 0.75$ & $23.2 \pm 19.9$ \\
\hline 50 & & $103 \pm 65$ & $3.61 \pm 1.61$ & $11.5 \pm 3.85$ & ND & $8.00 \pm 3.89$ & $22.4 \pm 9.57$ \\
\hline 75 & & $250 \pm 22$ & $2.41 \pm 0.25$ & $26.1 \pm 5.7$ & $165 \pm 14$ & $4.75 \pm 2.22$ & $22.3 \pm 8.84$ \\
\hline CTR & & $30 \pm 8$ & $7.85 \pm 0.42$ & $15.9 \pm 4.91$ & $8.25 \pm 2.47$ & $3.75 \pm 0.35$ & $21.7 \pm 20.2$ \\
\hline
\end{tabular}

CTR-Control; * Front-Impact area of berm; ${ }^{* *}$ Back-Non-impact area of berm.

about that of the control. Analysis of variance $(p=0.05)$ showed a significant difference in $\mathrm{Pb}, \mathrm{Cu}, \mathrm{Zn}, \mathrm{Cr}, \mathrm{Ni}$ and $\mathrm{Cd}$ levels distribution within the 0 to $75 \mathrm{~m}$ sampling points for both the impact and non impact areas of the berm. This indicates the degree of variability of soil metal levels within the locations. From the principal component biplot (Figure 3), the first two components accounted for $86.5 \%$ of the total metal variability in the studied soils. The first component (58.2\%) is a size variable indicating that the impact area which serve as the sink for spend bullet accounted for a significant level of $\mathrm{Pb}$ and $\mathrm{Cu}$ in the overall soils under study (Point to the Right). The points to the left (component 2\% - 28.3\%); the non-impact area and its surrounding farmland (0 - 75 $\mathrm{m})$ and the impact area surroundings $(0-75 \mathrm{~m})$ are clustered and associated, implying that metal levels within these areas showed no significant variation. Invariably, lead levels within the surrounding vicinity of the berm are correlated and arise from a similar source. Comparatively, Pb levels at the impact area $(17,500 \pm 3811 \mu \mathrm{g} / \mathrm{g})$ were significantly higher than previous study of $5680 \pm 2700 \mu \mathrm{g} / \mathrm{g}$, although levels at 10 to 75 m marks were about the same [18]. This indicates a threefold increase in $\mathrm{Pb}$ in a space of ten years from last previous study conducted in 2004 [18]. Soil property and weathering process may play a key role in the mineralization of spent bullets over time, hence this threefold increase. Lead levels at impact area of berm far exceeded the $400 \mu \mathrm{g} / \mathrm{g}$ USEPA limit used to guide clean-up effort of contaminated sites [28]. The surrounding non-impact area used mostly for agricultural purposes had $\mathrm{Pb}$ above the Canadian guide values of $70 \mu \mathrm{g} / \mathrm{g}$ for agricultural soils [29]. 


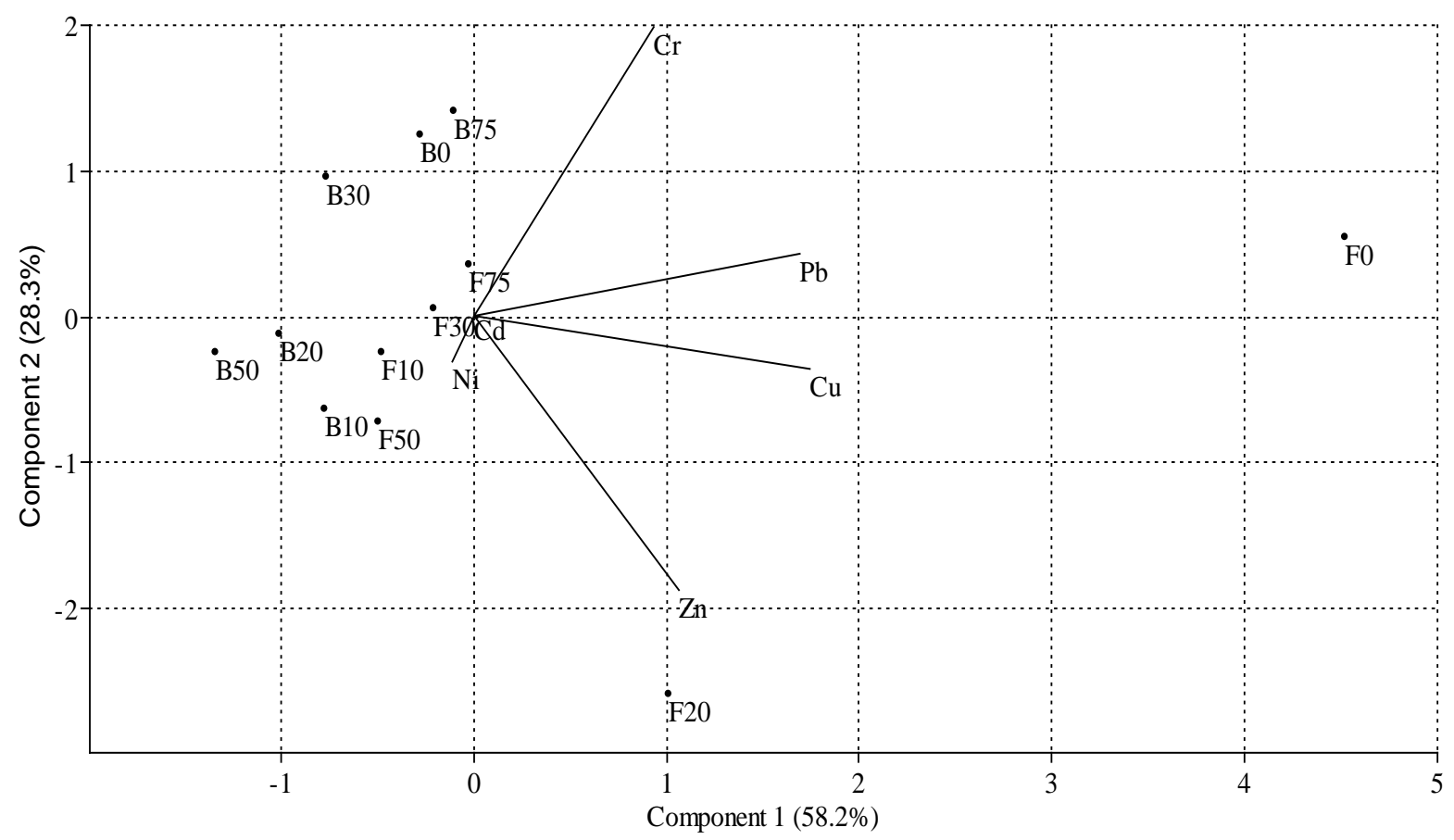

Figure 3. Principal component biplot of soil metal data set.

\subsection{Lead Distribution in Runoff Sediment}

Soil Pb levels of impact $(17,500 \pm 3811 \mu \mathrm{g} / \mathrm{g})$ and non-impact $(459 \pm 147 \mu \mathrm{g} / \mathrm{g})$ areas reflected in corresponding high levels of $\mathrm{Pb}$ in runoff sediment with respect to other metals (Table 4). Metal distribution order of $\mathrm{Pb}>\mathrm{Cu}>$ $\mathrm{Zn}>\mathrm{Cr}>\mathrm{Ni}>\mathrm{Cd}$ was similarly observed for runoff sediment. This geologically similar soil/sediment metal distribution patterns is mostly a reflection of activities around the berm area. Contamination was more pronounced at the impact area has earlier indicated in Table 3; therefore, sediments obtained from the runoff experiment recorded much higher concentrations of $\mathrm{Pb}$ within the various particle sizes $(0.43-0.15 \mathrm{~mm})$ compared to the non-impact area. This demonstrates likely presence of fine metallic bullet fragments resulting from initial and continuous aberration of bullet pellets with the soil and ongoing weathering process characterized by the tropical climate of the region. Particle size distribution of $\mathrm{Cu}$ closely resembles that of $\mathrm{Pb}$, with the impact area having higher $\mathrm{Cu}$ levels than the non impact area, owing to presence of corroded $\mathrm{Cu}$ jacketed bullet casings in the soil. Cadmium, $\mathrm{Cr}, \mathrm{Ni}$ and $\mathrm{Zn}$ levels in sediment fractions obtained from the impact and non impact areas were not significantly different from and were altogether about the same levels in control sample. Figure 4 shows the enrichment ratio of $\mathrm{Pb}$ in graded sediment fractions for three rainfall intensities. The enrichment ratio of $\mathrm{Pb}$ in sediment was higher in the $0.43 \mathrm{~mm}$ fractions, but steadily decreases to the $0.15 \mathrm{~mm}$ fractions (A and B). These observed trends were independent of the rainfall conditions. The $0.43 \mathrm{~mm}$ fractions appear to have the highest concentration of $\mathrm{Pb}$ because it includes actual $\mathrm{Pb}$ fragments that are wearing down over time. Thus, accelerated weathering of this fine particle of $\mathrm{Pb}$ is of environmental concern at most shooting range soils [14]. Incidentally, it is expected that high rainfall intensity will tend to wash-off more $\mathrm{Pb}$ particulates from surface soils. This is evident in slight increases observed in enrichment ratio of $\mathrm{Pb}$ in sediment obtained through the 200 $\mathrm{mm} / \mathrm{hr}$ intensity compared to the 80 and $150 \mathrm{~mm} / \mathrm{hr}$ rainfall conditions (Figure 5). Figure 6 shows cumulative sediment enrichment ratio of all the fractions $(0.43,0.25,0.18$ and $0.15 \mathrm{~mm})$ for increasing rainfall durations. The enrichment ratio of $\mathrm{Pb}$ for the cumulative sediment showed no appreciable increase over a prolong rainfall duration for the three intensities. This cuts across the impact and non-impact areas. An indication that longer rainfall may however not significantly lead to greater soil- $\mathrm{Pb}$ mobility. Considering the reducing soil $\mathrm{pH}$ condition, high organic matter and silt content of the berm and surrounding soils, $\mathrm{Pb}$ mobility in the soil may greatly be limited. This may in-part explain the relative decreasing soil-Pb concentration with increasing distances away from the impact and non-impact berm. On the other hand, the tropical climatic conditions of the study area (i.e. heavy rainfall for most part of the year) could possibly enhance the transport rate of particulate $\mathrm{Pb}$ across the 


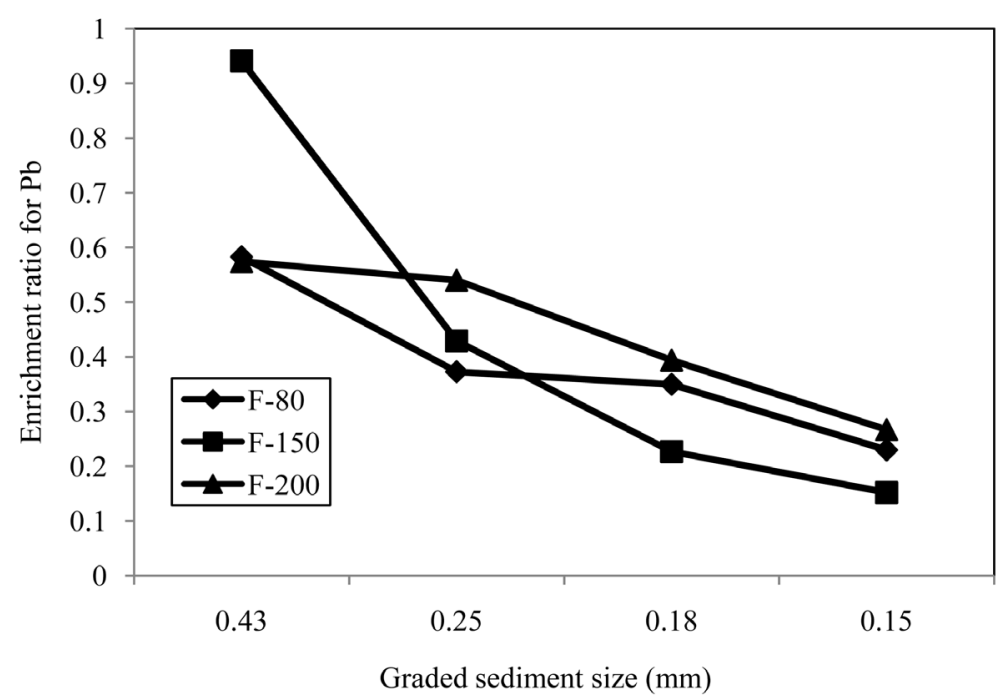

(a)



(b)

Figure 4. Enrichment ratio of lead in graded sediment size (a) impact (b) non-impact area.

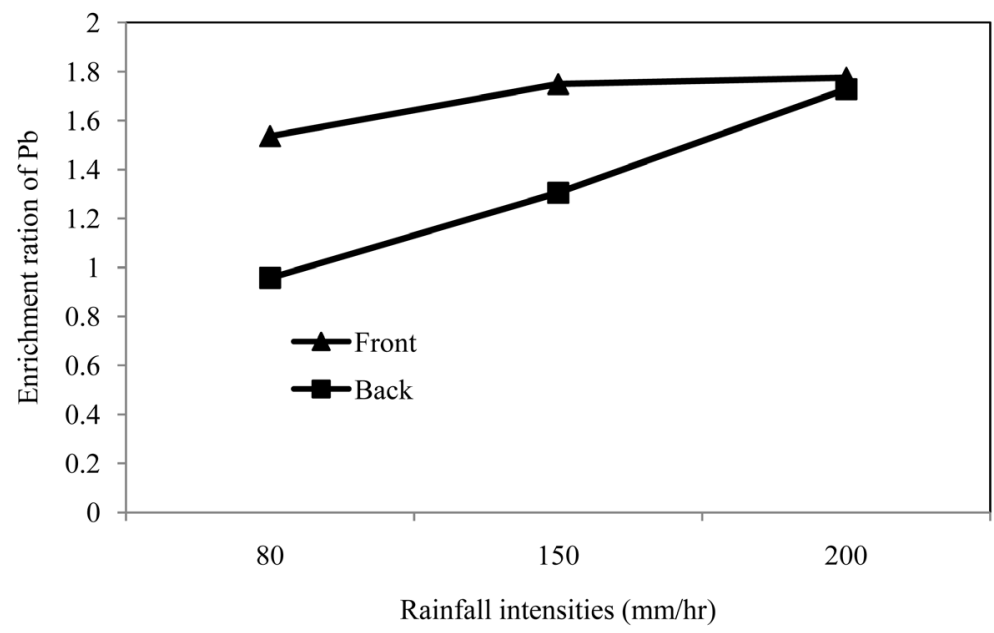

Figure 5. ER Distributions for different rainfall intensities. 


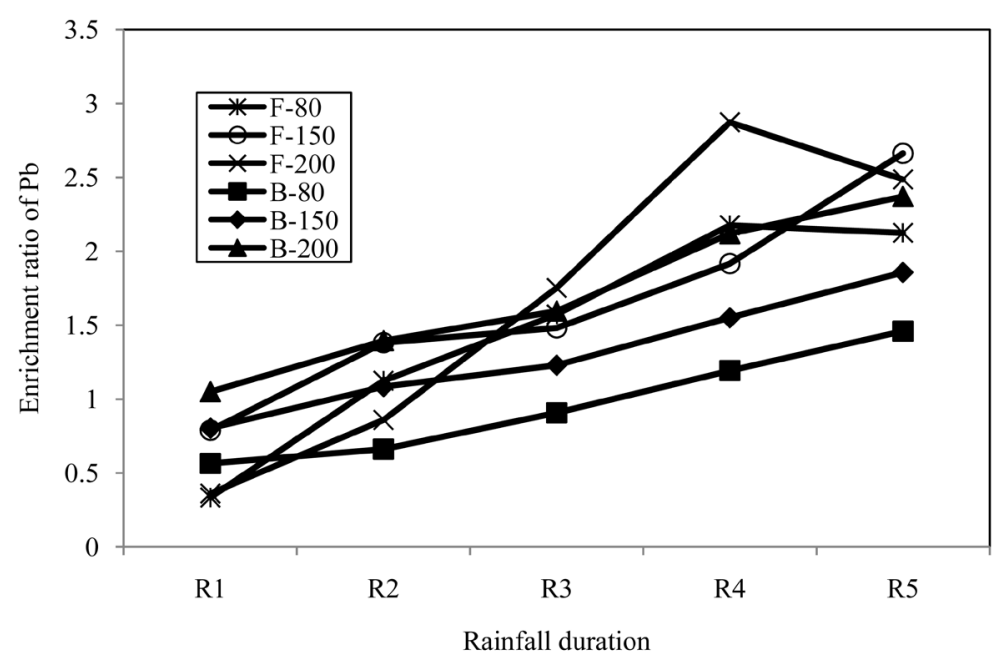

Figure 6. Cumulative sediment ER for different rainfall durations.

Table 4. Average metal levels ( $\mu \mathrm{g} / \mathrm{g})$ in runoff sediment.

\begin{tabular}{|c|c|c|c|c|c|c|c|}
\hline $\begin{array}{l}\text { Rainfall intensity } \\
\qquad(\mathrm{mm} / \mathrm{hr})\end{array}$ & $\begin{array}{l}\text { Particle Sizes } \\
\quad(\mathrm{mm})\end{array}$ & $\mathrm{Pb}$ & $\mathrm{Cd}$ & $\mathrm{Cr}$ & $\mathrm{Cu}$ & $\mathrm{Ni}$ & $\mathrm{Zn}$ \\
\hline \multirow[t]{4}{*}{ F-80 } & 0.43 & $10203 \pm 7189$ & $6.53 \pm 2.60$ & $68.4 \pm 30.4$ & $225 \pm 189$ & $12.3 \pm 4.21$ & $62.7 \pm 25.1$ \\
\hline & 0.25 & $6520 \pm 2552$ & $6.04 \pm 2.83$ & $23.3 \pm 9.11$ & $211 \pm 127$ & $5.01 \pm 2.67$ & $40.9 \pm 26.6$ \\
\hline & 0.18 & $6119 \pm 5969$ & $12.0 \pm 4.96$ & $44.5 \pm 36.9$ & $308 \pm 157$ & $9.07 \pm 3.13$ & $66.8 \pm 30.9$ \\
\hline & 0.15 & $4031 \pm 2951$ & $6.28 \pm 2.42$ & $23.1 \pm 6.01$ & $231 \pm 82$ & $7.75 \pm 5.81$ & $63.4 \pm 31.7$ \\
\hline \multirow[t]{4}{*}{ F-150 } & 0.43 & $16461 \pm 4476$ & $7.99 \pm 1.39$ & $38.5 \pm 27.9$ & $279 \pm 211$ & $14.5 \pm 7.66$ & $63.4 \pm 47.7$ \\
\hline & 0.25 & $7504 \pm 7504$ & $9.43 \pm 3.29$ & $28.5 \pm 13.0$ & $287 \pm 187$ & $5.10 \pm 2.07$ & $42.6 \pm 22.8$ \\
\hline & 0.18 & $3973 \pm 2641$ & $8.62 \pm 3.15$ & $21.1 \pm 16.1$ & $159 \pm 122$ & $7.64 \pm 5.50$ & $47.5 \pm 27.70$ \\
\hline & 0.15 & $2658 \pm 760$ & $6.68 \pm 2.21$ & $13.9 \pm 1.02$ & $157 \pm 83.9$ & $3.78 \pm 0.69$ & $35.59 \pm 2.62$ \\
\hline \multirow[t]{4}{*}{ F-200 } & 0.43 & $10039 \pm 6840$ & $5.35 \pm 2.94$ & $39.5 \pm 34.2$ & $216 \pm 114$ & $11.0 \pm 7.59$ & $28.7 \pm 32.8$ \\
\hline & 0.25 & $9444 \pm 6236$ & $5.78 \pm 2.17$ & $26.7 \pm 5.01$ & $251 \pm 207$ & $5.02 \pm 3.86$ & $29.7 \pm 24.6$ \\
\hline & 0.18 & $6894 \pm 6373$ & $5.42 \pm 1.84$ & $43.2 \pm 20.15$ & $253 \pm 167$ & $11.4 \pm 6.64$ & $32.4 \pm 20.5$ \\
\hline & 0.15 & $4664 \pm 4584$ & $8.46 \pm 7.52$ & $50.7 \pm 31.1$ & $440 \pm 347$ & $5.77 \pm 1.80$ & $119 \pm 113$ \\
\hline \multirow[t]{4}{*}{ B-80 } & 0.43 & $152 \pm 58.2$ & $7.36 \pm 4.70$ & $46.3 \pm 30.7$ & $24.6 \pm 20.5$ & $6.51 \pm .99$ & $58.0 \pm 48.5$ \\
\hline & 0.25 & $127 \pm 39.3$ & $13.0 \pm 5.71$ & $42.0 \pm 16.2$ & $45.4 \pm 48.2$ & $9.96 \pm 8.34$ & $38.3 \pm 29.9$ \\
\hline & 0.18 & $90.3 \pm 43.8$ & $9.20 \pm 3.64$ & $36.7 \pm 17.2$ & $12.5 \pm 22.7$ & ND & $80.9 \pm 18.4$ \\
\hline & 0.15 & $69.7 \pm 30.3$ & $26.0 \pm 27.4$ & 54. \pm 37.18 & ND & ND & $41.3 \pm 28.4$ \\
\hline \multirow[t]{4}{*}{ B-150 } & 0.43 & $207 \pm 78.4$ & $7.61 \pm 1.40$ & $2.90 \pm 1.08$ & $20.3 \pm 12.9$ & $7.40 \pm 2.99$ & $17.9 \pm 13.3$ \\
\hline & 0.25 & $145 \pm 34.3$ & $9.42 \pm 2.96$ & $11.9 \pm 7.33$ & $19.2 \pm 8.73$ & $8.96 \pm 6.11$ & $28.7 \pm 24.3$ \\
\hline & 0.18 & $136 \pm 40.0$ & $6.35 \pm 2.29$ & $2.77 \pm 1.42$ & $43.4 \pm 27.8$ & $17.8 \pm 22.8$ & $47.3 \pm 34.3$ \\
\hline & 0.15 & $111 \pm 39.8$ & $18.2 \pm 56$ & $9.27 \pm 5.07$ & ND & $9.55 \pm 9.09$ & $84.8 \pm 28.2$ \\
\hline \multirow[t]{4}{*}{ B-200 } & 0.43 & $269 \pm 82.4$ & $5.57 \pm 1.79$ & $64.7 \pm 16.6$ & $125 \pm 90$ & $7.0 \pm 3.7$ & $48.3 \pm 23.4$ \\
\hline & 0.25 & $189 \pm 48.9$ & $4.52 \pm 1.90$ & $16.2 \pm 8.74$ & $287 \pm 257$ & $13.0 \pm 18.1$ & $87.1 \pm 51.7$ \\
\hline & 0.18 & $182 \pm 61.8$ & $7.39 \pm 4.46$ & $35.7 \pm 15.5$ & $58.9 \pm 53.5$ & $9.17 \pm 6.74$ & $76.3 \pm 69.9$ \\
\hline & 0.15 & $153 \pm 66.4$ & $11.8 \pm 1.33$ & $68.0 \pm 72.2$ & $103 \pm 73$ & $19.1 \pm 14.6$ & $\mathrm{I} 23 \pm 179$ \\
\hline
\end{tabular}

F-Impact area of berm, B-Non impact area of berm. 
vicinity of the berm. These particulates could be carried long distances from source by the heavy rainfall runoff, which is evident in the high $\mathrm{Pb}$ concentration in the $0.43 \mathrm{~mm}$ fractions, thereby affecting uncontaminated soil ecosystem. These could further explain the high levels of Pb recorded in surrounding farmland soils (10 - $75 \mathrm{~m})$ behind the impact berm (Table 3).

Analysis of variance $(p=0.05)$ showed no significant differences in metal distribution across the sediment fractions of the three rainfall intensities at the impact area. However, for the non-impact area, there was a significant difference in the distribution of $\mathrm{Pb}, \mathrm{Cu}$ and $\mathrm{Cr}$ for the various sediment fractions. This further confirms that $\mathrm{Pb} \mathrm{Cu}$ and $\mathrm{Cr}$ are anthropogenically derived through spent shot deposition in the soils.

\subsection{Lead Levels in Surface Rainfall Runoff}

Surface rainfall runoffs obtained from the experiment similarly showed higher levels of $\mathrm{Pb}$ compared to other metals (Table 5). Runoffs obtained by the three rainfall intensities from the impact area soil had very high concentration of $\mathrm{Pb}(40.4$ - $65.6 \mu \mathrm{g} / \mathrm{ml})$ which exceeds the Toxicity Characteristic Leaching Procedure (TCLP) limits of $5 \mathrm{mg} / \mathrm{L}$ making it hazardous to the environment. A high lead level in the surface runoffs is an important indicator of soil-Pbmobility due to mineralization of particulate $\mathrm{Pb}$ bullets. Therefore, runoffs with this level of $\mathrm{Pb}$ possess significant potential of contaminating nearby surface water supply if any as well has cultivated farmlands found within the vicinity of the berm. Lead levels in surface runoffs from the impact area were found to significantly increase with increasing rainfall intensity and duration (Figure 7). Statistically, there was significant differences $(p=0.05)$ in metal distribution across the three rainfall intensities for the impact and non-impact areas, an indication of $\mathrm{Pb}$ variation in runoff between the impact and non-impact areas. Lead in runoff at the impact area is much higher in magnitude than $15-56 \mu \mathrm{g} / \mathrm{L}$ and 8.6 - $54 \mu \mathrm{g} / \mathrm{L}$ previously reported for in streams draining shooting ranges in Norway [15] [30].



Figure 7. Lead distribution in rainfall runoff for different rainfall durations.

Table 5. Average metal levels $(\mu \mathrm{g} / \mathrm{ml})$ in rainfall runoff water samples.

\begin{tabular}{|c|c|c|c|c|c|c|c|}
\hline Berm & Rainfall intensity (mm/hr) & $\mathrm{Pb}$ & $\mathrm{Cd}$ & $\mathrm{Cr}$ & $\mathrm{Cu}$ & $\mathrm{Ni}$ & $\mathrm{Zn}$ \\
\hline \multirow[t]{3}{*}{ Front } & F-80 & $40.4 \pm 20.0$ & $0.01 \pm 0.01$ & ND & $2.41 \pm 1.31$ & $0.02 \pm 0.02$ & $0.38 \pm 0.12$ \\
\hline & F-150 & $46.9 \pm 24.3$ & $0.02 \pm 0.01$ & ND & $1.68 \pm 0.48$ & $0.04 \pm 0.01$ & $0.62 \pm 0.38$ \\
\hline & F-200 & $65.6 \pm 32.1$ & $0.02 \pm 0.02$ & ND & $2.25 \pm 1.75$ & $0.04 \pm 0.01$ & $0.76 \pm 0.37$ \\
\hline \multirow[t]{3}{*}{ Back } & B-80 & $2.24 \pm 0.61$ & $0.04 \pm 0.02$ & $0.01 \pm 0.01$ & $0.02 \pm 0.01$ & $0.03 \pm 0.01$ & $0.30 \pm 0.11$ \\
\hline & B-150 & $2.69 \pm 1.51$ & $0.13 \pm 0.14$ & ND & $0.26 \pm 0.12$ & $0.03 \pm 0.01$ & $0.51 \pm 0.37$ \\
\hline & B-200 & $3.28 \pm 2.05$ & $0.04 \pm 0.02$ & $0.07 \pm 0.04$ & $0.14 \pm 0.14$ & $0.02 \pm 0.01$ & $0.32 \pm 0.33$ \\
\hline
\end{tabular}




\section{Conclusion}

Elevated concentrations of $\mathrm{Pb}$ were found in soils at the impact area of the berm. This translated to higher enrichment ratio of $\mathrm{Pb}$ in sediment, particularly the $0.43 \mathrm{~mm}$ fractions obtained from the rainfall runoff experiment. The presence of metallic bullet fragment significantly explains the variations in enrichment ratio for the different fractions. The enrichment ratios of $\mathrm{Pb}$ in sediment increased with higher rainfall intensity but showed no appreciable increase for prolong rainfall duration. Although reducing $\mathrm{pH}$ condition, organic matter and silt content of the soils may limit migration of $\mathrm{Pb}$, increasing rainfall intensity characterized by the tropical humid climate of the study site will invariably lead to migration of corroded metallic $\mathrm{Pb}$ particles. This clearly accounts for the high $\mathrm{Pb}$ levels recorded in surrounding farmlands few meters away from the non-impact area of the berm. Surface runoff from the impact area was obviously contaminated with levels of $\mathrm{Pb}$ far exceeding TCLP limits of $5 \mathrm{mg} / \mathrm{L}$ which possess even greater risk of contaminating surrounding farmlands. It can be concluded, that $\mathrm{Pb}$ levels within the cultivated farmlands behind the berm and the general surroundings areas were strongly related to mobility of fine metallic $\mathrm{Pb}$ particulates from the impact berm soil as a result of heavy and continuous rainfall runoffs event. These could have extensive implications in terms of availability and possible bioaccumulation of $\mathrm{Pb}$ in agricultural production obtained within the area. It is, therefore, imperative for closer monitoring and possible remediation to void further and prolong contamination of arable farmlands around the range.

\section{References}

[1] Ahmad, M., Hashimoto, Y., Moon, D.H., Lee, S.S. and Ok, Y.S. (2012) Immobilization of Lead in a Korean Military Shooting Range Soil Using Eggshell Waste: An Integrated Mechanistic Approach. Journal of Hazardous Materials, 209/210, 392-401. http://dx.doi.org/10.1016/j.jhazmat.2012.01.047

[2] Cao, X., Ma Jr., L.Q., Hardison, D.W. and Harris, W.G. (2003) Weathering of Lead Bullets and Their Environmental Effects at Outdoor Shooting Ranges. Journal of Environmental Quality, 32, 526-534. http://dx.doi.org/10.2134/jeq2003.5260

[3] Wan, X., Tandy, S., Hockmann, K. and Schulin, R. (2013) Changes in Sb Speciation with Waterlogging of Shooting Range Soils and Impacts on Plant Uptake. Environmental Pollution, 172, 53-60. http://dx.doi.org/10.1016/j.envpol.2012.08.010

[4] Lamporte-Saumure, M., Martel, R. and Mercier, G. (2011) Evaluation of Phytochemical Methods for Treatment of Cu, pb, Sb, and Zn in Canadian Small Arm Firing Ranges Backtop Soils. Water, Air, and Soil Pollution, 213, 171-189.

[5] Ahmad, M., Lee, S.S., Moon, D.H., Yang, J.E. and Ok, Y.S. (2011) A Review of Environmental Contamination and Remediation Strategies for Heavy Metals at Shooting Range Soils. In: Malik, A. and Grohmann, E., Eds., Environmental Protection Strategies for Sustainable Development, Springer, New York, 437-452.

[6] Clausen, J. and Korte, N. (2009) The Distribution of Metals in Soils and Pore Water at Three U.S. Military Training Facilities. Soil and Sediment Contamination, 18, 546-563. http://dx.doi.org/10.1080/15320380903085683

[7] Laporte-Saumure, M., Martel, R. and Mercier, G. (2012) Pore Water Quality in the Upper Part of the Vadose Zone under an Operating Canadian Small Arms Firing Range Backstop Berm. Soil and Sediment Contamination, 21, 739755. http://dx.doi.org/10.1080/15320383.2012.691576

[8] Mannnien, S. and Tanskanen. N. (1993) Transfer of Lead from Shotgun Pellets to Humus and Three Plant Species in Finish Shooting Range. Archived of Environmental Contamination and Toxicology, 24, 410-414. http://dx.doi.org/10.1007/BF01128741

[9] Mellor, A. and McCartney, C. (1994) The Effects of Lead Shot Deposition on Soils and Crops at a Clay Pigeon Shooting Site in Northern England. Soil Use Management, 10, 124-129. http://dx.doi.org/10.1111/j.1475-2743.1994.tb00472.x

[10] Murray, K.B.A., Carter, C., Ehlert, A., Harris, A., Kopec, M., Richardson, J. and Sokol, H. (1997) Distribution and Mobility of Lead in Soils at an Outdoor Shooting Range. Journal of Soil Contamination, 6, 79-93. http://dx.doi.org/10.1080/15320389709383547

[11] Rooney, C.P., Mclaren, R.C. and Cresswell, R.J. (1999) Distribution and Phytoavailability of Lead in a Soil Contaminated with Lead Shot. Water Air and Soil Pollution, 116, 535-548. http://dx.doi.org/10.1023/A:1005181303843

[12] Stansley, W. and Roscoe, D.E. (1996) The Uptake and Effects of Lead in Small Mammals and Frogs at a Trap and Skeet Range. Archived of Environmental Contamination and Toxicology, 30, 220-226. http://dx.doi.org/10.1007/BF00215801

[13] Van Vleek, B., Amarasiriwardena, D. and Xing, B. (2011) Investigation of Distribution of Soil Antimony Using Sequential Extraction and Antimony Complexed to Soil-Derived Humic Acids Molar Mass Fractions Extracted from 
Various Depths in a Shooting Range Soil. Microchemistry Journal, 97, 68-73. http://dx.doi.org/10.1016/j.microc.2010.05.015

[14] Hardison, D.W., Ma, L.Q., Luongo, T. and Harris, W.G. (2004) Lead Contamination in Shooting Range Soils from Abrasion of Lead Bullets and Subsequent Weathering. Science of the Total Environment, 328, 175-183. http://dx.doi.org/10.1016/j.scitotenv.2003.12.013

[15] Heier, L.S., Meland, S., Ljones, M., Salbu, B. and Stromseng, A.E. (2010) Short-Term Temporal Variations in Speciation of $\mathrm{Pb}, \mathrm{Cu}, \mathrm{Zn}$ and $\mathrm{Sb}$ in a Shooting Range Runoff Stream. Science of the Total Environment, 408, 2409-2417. http://dx.doi.org/10.1016/j.scitotenv.2010.02.019

[16] Hafzullah, A., Erdem, U.N., Sevket, C., Abdullah, G., Jaeyoung, Y., Kaan, K., Boran, I.S. and Ebru, E. (2012) A Rainfall Simulator for Laboratory-Scale Assessment of Rainfall-Runoff-Sediment Transport Processes over a TwoDimensional Flume. Catena, 98, 63-72. http://dx.doi.org/10.1016/j.catena.2012.06.009

[17] Zheng, Y., Luo, X., Zhang, W., Wu. B., Han, F., Lin, Z. and Wang, X. (2012) Enrichment Behavior and Transport Mechanism of Soil-Bound PAHs during Rainfall-Runoff Events. Environmental Pollution, 171, 85-92. http://dx.doi.org/10.1016/j.envpol.2012.07.030

[18] Etim, E.U. and Onianwa, P.C. (2012) Lead Contamination of Soil in the Vicinity of a Military Shooting Range in Ibadan, Nigeria. Toxicological and Environmental Chemistry, 94, 895-905. http://dx.doi.org/10.1080/02772248.2012.678997

[19] Bouyoucos, G.H. (1951) A Recalibration of the Hydrometer for Making Mechanical Analysis of Soils. Agronomy Journal, 43, 434-438. http://dx.doi.org/10.2134/agronj1951.00021962004300090005x

[20] Walkley, A. and Black, I.A. (1934) An Examination of the Degtjareff Method for Determining Soil Organic Matter and Proposed Modification of the Chromic Acid Titration Method. Soil Science, 37, 29-38. http://dx.doi.org/10.1097/00010694-193401000-00003

[21] Andersson, A. (1976) On the Determination of Ecologically Significant Fractions of Heavy Metals in Soils. Swedish Journal of Agricultural Research, 6, 19-25.

[22] Hignett, C.T., Gusli, S., Cass, A. and Besz, W. (1995) An Automated Laboratory Rainfall Simulation System with Controlled Rainfall Intensity, Raindrop Energy and Soil Drainage. Soil Technology, 8, 31-42. http://dx.doi.org/10.1016/0933-3630(95)00004-2

[23] Duggan, D. and Dhawan, A. (2007) Speciation and Vertival Distribution of Lead and Lead Shots in Soil at a Recreational Firing Range. Soil and Sediment Contamination, 16, 351-369. http://dx.doi.org/10.1080/15320380701404425

[24] Dermatas, D., Cao, X., Tsaneva, V., Shen, G. and Grubb, D. (2006) Fate and Behavior of Metal(loid) Contaminants in an Organic Matter Rich Shooting Range Soil: Implications for Remediation. Water Air and Soil Pollution Focus, 6, 143-155. http://dx.doi.org/10.1007/s11267-005-9003-4

[25] Robinson, B.H., Bischofberger, S., Stoll, A., Schroer, D., Furrer, G., Roulier, S., Gruenwald, A., Attinger, W. and Schulin, R. (2008) Plant Uptake of Trace Elements on a Swiss Military Shooting Range: Uptake Pathways and Land Management Implications. Environmental Pollution, 153, 668-676. http://dx.doi.org/10.1016/j.envpol.2007.08.034

[26] Sanderson, P., Naidu, R., Bolan, N., Bowman, M. and Mclure, S. (2012) Effect of Soil Type on Distribution and Bioaccessibility of Metal Contaminants in Shooting Range Soils. Science of the Total Environment, 438, 452-462. http://dx.doi.org/10.1016/j.scitotenv.2012.08.014

[27] Spuller, C., Weigand, H. and Marb, C. (2007) Trace Metal Stabilization in a Shooting Range Soil: Mobility and Phytotoxicity. Journal of Hazardous Material, 141, 375-387. http://dx.doi.org/10.1016/j.jhazmat.2006.05.082

[28] United State Environmental Protection Agency, US EPA (2002) Supplemental Guidance for Developing Soil Screening Levels for Superfund Sites. Office of Solid Waste and Emergency Response, Washington DC.

[29] Canadian Council of Ministers of the Environment (CCME) (2007) Canadian Soil Quality Guidelines for the Protection of Environmental and Human Health: Summary Tables. Canadian Environmental Quality Guidelines, 2007. Canadian Council of Ministers of the Environment, Winnipeg.

[30] Mariussen, E., Ljones, M. and Stromseng, A.E. (2012) Use of Sorbents for Purification of Lead, Copper and Antimony in Runoff Water from Small Arms Shooting Range. Journal of Hazardous Materials, 243, 95-104. http://dx.doi.org/10.1016/j.jhazmat.2012.10.005 